\title{
Desain Sistem Refrigerated Sea Water $(R S W)$ pada Kapal Ikan Pelat Datar 10 GT
}

\author{
Zulkifli $^{1}$, Baharuddin ${ }^{1 *}$, Andi Husni Sitepu ${ }^{1}$, Muhammad Farid ${ }^{1}$ \\ ${ }^{1}$ Departemen Teknik Sistem Perkapalan, Fakultas Teknik, Universitas Hasanuddin, Makassar \\ Jl. Poros Malino km. 6, Bontomarannu, Kabupaten Gowa, Sulawesi Selatan 92171 \\ *Email: baharmarine@yahoo.com
}

DOI: 10.25042/jpe.052019.06

\begin{abstract}
Abstrak
Desain sistem $R S W$ dalam penelitian ini ditujukan untuk penerapan di kapal ikan Pelat Datar berlisensi berkapasitas 10 GT. Desain badan kapal ini merupakan sebuah terobosan baru karena badan/lambung kapal dibuat tanpa ada lekukan pelat samasekali. Badan kapal terbuat dari baja dengan proses pembuatan terbilang singkat, berbiaya murah sehingga layak digunakan oleh nelayan lokal/tradisional di Indonesia. Refrigerated Sea Water (RSW) adalah sebuah sistem pendingin dengan sistem sirkulasi air laut yang didinginkan oleh refrigerator. Komponen utama RSW terdiri dari kompresor, kondensor, evaporator dan refrigeran. Hasil desain $R S W$ untuk kapal ikan pelat datar meliputi; penetuan ketebalan dan jenis isolasi palka, pemilihan sistem dan jenis refrigeran, perancangan dan pemilihan komponen utama RSW, penentuan keyplan serta layout sistem RSW. Hasil desain $R S W$ ditujukan untuk mempertahankan suhu ruangan palka ikan sebesar $5{ }^{\circ} \mathrm{C}$, bobot muatan ikan sekitar 12,276 ton ikan tuna dengan durasi operasi selama 24 jam.
\end{abstract}

\begin{abstract}
Refrigerated Sea Water (RSW) System Design on a 10 GT Flat Plate Fishing Boat. The RSW system design in this study is intended for the application of 10 GT licensed Flat Plate fishing vessels. The design of the ship's body is a new breakthrough because the body / hull of the ship is made without any plate curves at all. The ship's body made of steel with a manufacturing process is fairly short, low cost so that it is suitable for use by local / traditional fishermen in Indonesia. Refrigerated Sea Water (RSW) is a cooling system with a circulation system of seawater cooled by a refrigerator. The main components of RSW consist of a compressor, condenser, evaporator and refrigerant. RSW design results for flat plate fishing vessels include; determination of thickness and type of hold insulation, system selection and type of refrigerant, design and selection of RSW main components, determination of keyplan and RSW system layout. The RSW design was intended to maintain the temperature of the fish hold room at $5{ }^{\circ} \mathrm{C}$, the weight of the fish load around 12.276 tons of tuna with a duration of operation for 24 hours.
\end{abstract}

Kata Kunci: Beban pendinginan, komponen RSW, kapal ikan, pelat datar berlisensi

\section{Pendahuluan}

Kapal perikanan adalah kapal yang digunakan dalam kegiatan perikanan yang mencakup penggunaan atau aktivitas penangkapan atau mengumpulkan sumber daya di perairan laut, serta penggunaan dalam beberapa aktivitas seperti riset, training dan inspeksi sumber daya perairan.

Beragam sistem pendinginan muatan pada kapal ikan kerap dijumpai mulai dari sistem tradisional yakni menggunakan campuran es balok sampai kepada sistem pendinginan yang lebih modern. Tujuan diadakan sistem pendingin pada palka (chilling storage) kapal ikan untuk menjaga mutu ikan selama proses penangkapan maupun proses transportasi ikan hasil tangkapan ke darat [1].

Salah satu sistem pendingin yang banyak digunakan saat ini adalah Refrigerated Sea Water (RSW). Refrigerated sea water (RSW) adalah sebuah sistem pendingin dengan sistem sirkulasi air laut yang didinginkan oleh refrigerator. Komponen utama RSW terdiri dari kompresor, kondensor, evaporator dan refrigeran [2]. Sistem RSW secara umum adalah mengalirkan refrigerant untuk mendinginkan air laut yang berfungsi sebagai media pendingin utama di ruang muat kapal. 
Pertimbangan paling mendasar dalam penggunaan sistem pendingin ini ialah volume palka dapat dimaksimalkan karena tidak membutuhkan volume yang besar untuk komponen sistem RSW-nya, serta penurunan suhu ikan akan berlangsung lebih cepat karena suhu permukaan ikan dapat berkontak langsung dengan media pendingin.

\section{Metode}

Objek yang digunakan dalam penelitian ini adalah sebuah kapal ikan Pelat Datar berlisensi dengan kapasitas 10 GT. Desain badan kapal ini merupakan sebuah terobosan karena bodi/lambung kapal dibuat tanpa ada lekukanpelat samasekali. Badan kapal terbuat dari baja dengan proses pembuatan terbilang singkat, berbiaya murah serta layak digunakan oleh nelayan lokal/tradisional di Indonesia.

Tabel 1. Utama kapal pelat datar 10 GT

\begin{tabular}{lc}
\hline \multicolumn{1}{c}{ Ukuran } & Nominal \\
\hline Panjang (LOA) & $15 \mathrm{~m}$ \\
Lebar (B) & $4,075 \mathrm{~m}$ \\
Tinggi (H) & $2,39 \mathrm{~m}$ \\
Sarat (T) & $1,2 \mathrm{~m}$ \\
Kecepatan (V) & $7-9$ Knot \\
\hline
\end{tabular}

Disain sistem pendingin Refrigerated Sea Water $(R S W)$ dilakukan dengan mempertimbangkan beban kalor dari muatan ikan serta beban pendingin dari air laut itu sendiri.

Secara umum desain RSW meliputi tahapantahapan;

- Menghitung beban kalor palka

- Pemilihan sistem dan refrigeran

- Perancangan serta pemilihan komponen,

- Menggambar keyplan sistem atau diagram alur

- Mendesain layout sistem RSW
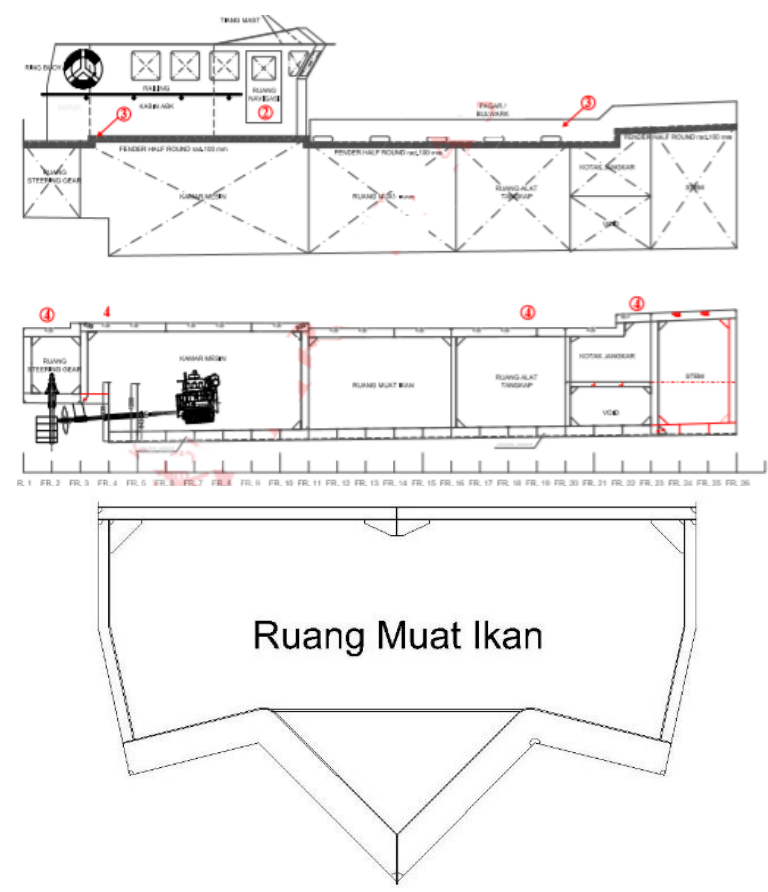

Gambar 1. Ruang palka kapal ikan pelat datar

\section{Desain Refrigerated Sea Water (RSW)}

\subsection{Penentuan Kapasitas Ruang Muat}

Jika volume ruang muat palka adalah :

$$
\begin{aligned}
\mathrm{V} & =\text { Luas Ruang Muat } \times \text { Panjang Palka } \\
& =5,4560 \mathrm{~m}^{2} \times 3 \mathrm{~m} \\
& =16,368 \mathrm{~m}^{3}
\end{aligned}
$$

dengan stowage factor 0,75 untuk ikan tuna maka kapasitas ruang muat palka:

Kapasitas $=$ Volume Palka $\mathrm{x}$ Stowage Factor

$$
\begin{aligned}
& =16,368 \mathrm{~m}^{3} \times 0,75 \text { ton } / \mathrm{m}^{3} \\
& =12,276 \text { ton }
\end{aligned}
$$

\subsection{Pemilihan Isolasi Palka}

Isolasi ini berfungsi untuk mempertahankan suhu ruangan palka dengan mencegah adanya kalor yang masuk dan keluar dari palka. Polyuretane dianggap sebagai isolasi paling baik karena memiliki konduktivitas termal yang kecil. 
Tabel 2. Karakteristik polyurethane

\begin{tabular}{lc}
\hline \multicolumn{1}{c}{ Material } & $\begin{array}{c}\text { Expanded } \\
\text { Polyurethane }\end{array}$ \\
\hline Densitas $\left(\mathrm{Kg} / \mathrm{m}^{2}\right)$ & 40 \\
Kond. Thermal & 0,02 \\
$\left(\mathrm{Kkal} / \mathrm{m}\right.$ jam $\left.{ }^{\circ} \mathrm{C}\right)$ & Baik \\
Kekedapan & Jelek \\
Keamanan dari Api & 3000 \\
Kekukatan kompresi $\left(\mathrm{Kg} / \mathrm{m}^{2}\right)$ & Sedang \\
Harga & Tinggi \\
Biaya Pasang & \\
\hline
\end{tabular}

Penggunaan dan susunan bahan isolasi ruang palka akan menentukan kemampuan palka dalam mengisolasi keluar masuknya kalor.

Tabel 3. Susunan dinding palka

\begin{tabular}{lccc}
\hline Nama Bahan & $\begin{array}{c}\text { Konduktivitas } \\
\text { Thermal } \\
\left(\mathbf{k k a l} / \mathbf{m ~ s} \mathbf{~}^{\circ} \mathbf{C}\right)\end{array}$ & $\begin{array}{c}\text { Tebal } \\
\text { Bahan } \\
(\mathbf{m})\end{array}$ & X/K \\
\hline Pelat Baja & $110 \times 10^{-4}$ & 0,005 & 0,45 \\
Polyurethane & $0,06 \times 10^{-4}$ & 0,05 & 8333,33 \\
Alumunium & $500 \times 10^{-4}$ & 0,003 & 0,06 \\
\hline
\end{tabular}

Beban kalor palka terdiri dari beban transmisi, radiasi, infiltrasi, perorangan maupun beban produk. Perhitungan luas permukaan yang terkena beban transmisi diperoleh $16,5139 \mathrm{~m}^{2}$, maka transmisi yang diterima oleh dinding utama palka sebesar $0,06 \mathrm{kkal} / \mathrm{s}$ atau sebesar $0,16 \mathrm{~kW}$.

Jika luas permukaan yang terkena beban radiasi sebesar 20,09 $\mathrm{m}^{2}$, serta koefisien perpindahan panas sebesar:

$$
\begin{aligned}
\mathrm{U}= & 0,00012 \mathrm{Kkal} / \mathrm{m}^{2} \mathrm{~s} \\
\mathrm{Q} 2= & 0,00012 \mathrm{Kkal} / \mathrm{m}^{2} \mathrm{~s} \times 20,8094 \mathrm{~m}^{2} \\
& \mathrm{x}(34-5){ }^{\circ} \mathrm{C} \\
= & 0,06 \mathrm{Kkal} / \mathrm{s}
\end{aligned}
$$

Maka selanjutnya diperoleh beban radiasi pada dinding palka sebesar $0,06 \mathrm{kKal} / \mathrm{s}$ atau sebesar $0,25 \mathrm{~kW}$.

Beban panas produk ikan adalah beban kalor yang terdapat dalam tubuh ikan, dimana ikan Tuna yang memiliki panas jenis sebesar $3,43{ }^{\circ} \mathrm{C}$ $\mathrm{kJ} / \mathrm{kg}$ [3], maka beban panas ikan:

$$
\begin{aligned}
\mathrm{Q} 3 & =3,43 \mathrm{~kJ} / \mathrm{kg}^{\circ} \mathrm{Cx} 12276 \mathrm{~kg} \times(28-5){ }^{\circ} \mathrm{C} \\
& =968453,64 \mathrm{Kj} \\
& =269,01 \mathrm{Kj} / \mathrm{s}
\end{aligned}
$$

Jadi, Beban kalor produk yaitu beban kalor yang diserap oleh ikan tuna ialah sebesar 269,01 $\mathrm{kW}$.

Selanjutnya diperoleh beban kalor keseluruhan dari akumulasi beban-beban di atas sebesar;

$$
\begin{aligned}
\mathrm{Q} & =\mathrm{Q} 1+\mathrm{Q} 2+\mathrm{Q} 3 \\
& =0,16+0,25+269,01 \\
& =269,43 \mathrm{~kW}
\end{aligned}
$$

Berdasarkan pertimbangan karakteristik beberapa jenis refrigerant, pilihan dijatuhkan pada refrigerant $R 22$ yang memiliki efek refrigerasi yang tinggi serta harga yang murah [4].

Besarnya daya kompresor dipengaruhi oleh laju aliran massa dan suhu yang akan dicapai pada palka sebesar $5{ }^{\circ} \mathrm{C}$, serta laju aliran massa $(\dot{\mathrm{m}})$ pada pipa $3 / 4 "$ di $0{ }^{\circ} \mathrm{C}\left(1282 \mathrm{~kg} / \mathrm{m}^{3}\right)$ pada kecepatan $4 \mathrm{~m} / \mathrm{s}$ berada pada rentang $0,13904 \mathrm{~kg} / \mathrm{s}$ sampai $1.4102 \mathrm{~kg} / \mathrm{s}$.

Jika nilai kerja kompresor pada kecepatan 4 $\mathrm{m} / \mathrm{s}$ dengan $\mathrm{h}_{1}=405 \mathrm{~kJ} / \mathrm{kg}$ pada suhu $0{ }^{\circ} \mathrm{C}$ dan tekanan 4,98 bar, dan nilai $\mathrm{h}_{2}=457 \mathrm{~kJ} / \mathrm{kg}$ pada suhu $83{ }^{\circ} \mathrm{C}$ dan tekanan 13 bar [5]. Maka kerja kompresor adalah;

$$
\begin{aligned}
\mathrm{W} & =(0.564)(405-457) \\
& =-29.30 \mathrm{~kW}
\end{aligned}
$$

Panas yang dibuang kondensor dengan $\mathrm{h}_{3}=$ $416.5 \mathrm{~kJ} / \mathrm{kg}$ pada tekanan 13 bar dengan suhu $35{ }^{\circ} \mathrm{C}$. Maka nilai Q cond adalah:

$$
\begin{aligned}
Q & =(0.564)(416.5-457) \\
& =-26.48 \mathrm{~kW}
\end{aligned}
$$

Pengaruh karakteristik refrigerant menyebabkan variasi kalor yang dibuang ke kondensor yakni sebesar 2,93 kW sampai dengan $47,69 \mathrm{~kW}$. 
Koefisien perpindahan panas menyeluruh pada pipa evaporator akan mempengaruhi dimensi evaporator. Jika suhu evaporator dari rentang $5{ }^{\circ} \mathrm{C}$ s/d $\quad 0 \quad{ }^{\circ} \mathrm{C}$, maka $\mathrm{Q}_{\text {evaporator dihitung dengan }}$ menggunakan persamaan:

$$
Q_{\text {evaporator }}=M_{S W} \cdot C p_{S W}\left(T_{\text {awal }}-T_{\text {akhir }}\right)
$$

Qevaporator dengan rentang suhu pada $0{ }^{\circ} \mathrm{C}$ s/d $5{ }^{\circ} \mathrm{C}$ yakni sebesar $107,35 \mathrm{~kW}$ sampai dengan $130,62 \mathrm{~kW}$, dan estimasi panjang pipa evaporator diperoleh antara 11,513 m s/d 14,008 m.

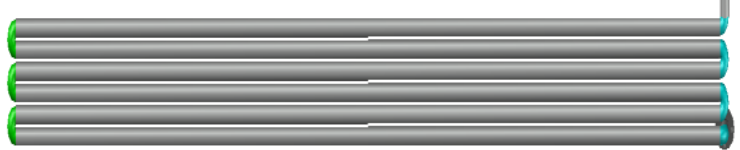

Gambar 2. Bentuk dan panjang pipa evaporator pada palka

Untuk refrigerant $\mathrm{R} 22$ dengan efek refrigerasi sebesar 162,67 kJ/kg, maka nilai entalpi dan tekanan sebagaimana pada Gambar 3 di bawah ini.

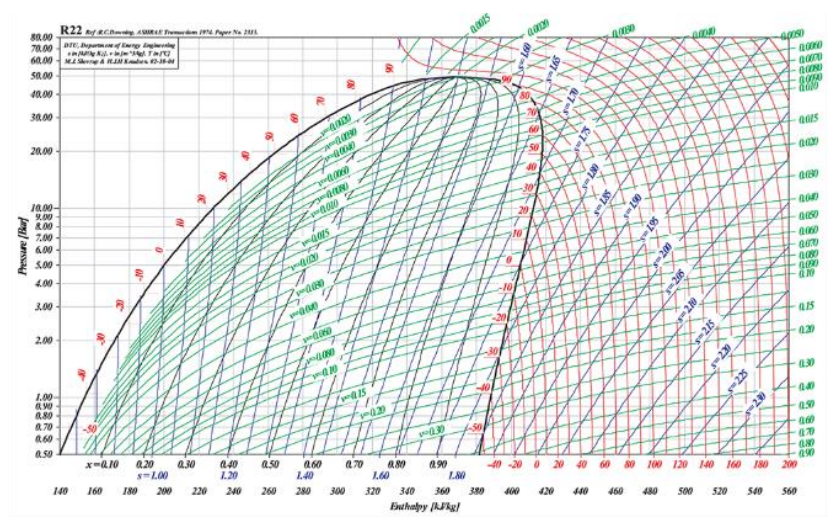

Gambar 3. Diagram pressure dan entalpi refrigerant $\mathrm{R} 22$

Tingkat keadaan refrigerant R22 pada kondisi operasi sistem sebagai berikut:
$\mathrm{T}_{\text {eva }}=0{ }^{\circ} \mathrm{C}$
$\mathrm{h}_{1}=405 \mathrm{~kJ} / \mathrm{kg}$
$\mathrm{T}_{\text {cond }}=83^{\circ} \mathrm{C}$
$\mathrm{h}_{2}=457 \mathrm{~kJ} / \mathrm{kg}$
$\mathrm{P}_{\text {eva }}=4,98$ bar
$\mathrm{h}_{3}=416,5 \mathrm{~kJ} / \mathrm{kg}$
$\mathrm{P}_{\text {cond }}=13$ bar
$\mathrm{h}_{4}=416,5 \mathrm{~kJ} / \mathrm{kg}$

Berdasarkan spesifikasi di atas maka jenis kompresor tipe Dorin H32H743CC dengan spesifikasi

Tabel 4. Spesifikasi kompresor H32H743CC

\begin{tabular}{ccccc}
\hline $\begin{array}{c}\text { Temp. } \\
\text { Condensor }\end{array}$ & \multicolumn{2}{c}{$\begin{array}{c}\text { Kerja } \\
\text { Kompressor } \\
\end{array}$} & \multicolumn{2}{c}{$\begin{array}{c}\text { Daya } \\
\text { Kompressor } \\
\mathbf{P}(\mathbf{W})\end{array}$} \\
\hline \multirow{2}{*}{$\mathbf{C}$} & $\mathbf{T}=$ & $\mathbf{T}=$ & $\mathbf{T}=$ & $\mathbf{T}=$ \\
& $\mathbf{0}^{\circ} \mathbf{C}$ & $\mathbf{5}^{\circ} \mathbf{C}$ & $\mathbf{0}^{\circ} \mathbf{C}$ & $\mathbf{5}^{\circ} \mathbf{C}$ \\
\hline 35 & 25040 & 29660 & 7,10 & 7,58 \\
45 & 21890 & 26110 & 7,62 & 8,14 \\
\hline
\end{tabular}

Pemilihan kondensor berdasarkan karakteristik suhu input yang mampu diterima, tekanan kerja, laju aliran refrigerant serta kapasitas daya kondensor. Berdasarkan parameter diatas maka dipilih kondensor Bluecold $61614 \mathrm{H}$.

Terdapat dua pompa yang dibutuhkan, yakni pompa untuk pendinginan kondensor dan pompa air laut untuk pemindahan air laut ke dalam palka. Dengan laju aliran yang sebesar $5,18 \mathrm{~m}^{3} / \mathrm{jam}$ dengan head total 2,586 $\mathrm{m}$ serta efisiensi 0,75 maka dipilih pompa AZCUE MO11/10 80-A dengan daya $0,5 \mathrm{~kW}$.

Dalam pemilihan pompa air laut, diasumsikan bahwa ruang palka akan terisi sampai 0,25\% volume palka atau sebesar $4,855 \mathrm{~m}^{3}$ dan dalam waktu 30 menit. Maka pilihan pompa yang tepat adalah AZCUE MO11/10 80-A dengan daya 0,5 $\mathrm{kW}$.

\subsection{Keyplan Sistem}

Perencanaan keyplan sistem didasarkan pada pemilihan komponen dengan rangkaian masingmasing komponen sehingga terbentuk sebuah sistem pendingin RSW sebagaimana pada gambar di bawah ini.

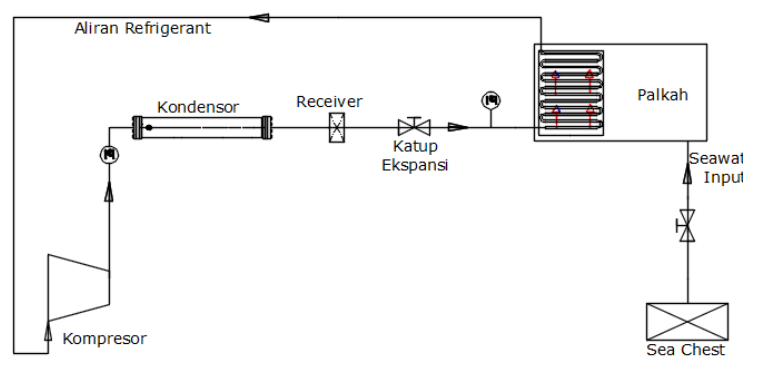

Gambar 4. Keyplan sistem RSW 
Sistem RSW secara umum adalah mengalirkan refrigerant untuk mendinginkan air laut. Kerja pertama dilakukan oleh kompresor untuk mengeluarkan udara panas bertekanan tinggi menuju ke kondensor. Setelah itu katup ekspansi dibuka sehingga refrigerant dari receiver dilepas untuk menuju ke evaporator sehingga refrigerant cair bertekanan tinggi berubah menjadi refrigerant cair bertekenan rendah.

Setelah itu refrigerant cair tersebut masuk ke dalam evaporator dan mengambil panas dari air laut atau udara sehingga refrigerant cair berubah menjadi uap bertekanan rendah. Refrigerant dalam bentuk uap bertekanan rendah ini lalu dikompresikan dengan kompresor sehingga berubah bentuk menjadi gas bertekanan tinggi. Lalu refrigerant yang berbentuk gas bertekanan tinggi ini lalu bersirkulasi di kondensor dengan air sehingga refrigerant tersebut berubah menjadi cairan bertekanan tinggi.

Setelah mengalami proses pendinginan di kondensor refrigerant kemudian dialirkan ke receiver. Dari receiver refrigerant melewati katup ekspansi menuju ke evaporator dalam bentuk cairan dengan suhu yang sangat rendah. Selanjutnya di evaporator refrigerant berinteraksi dengan air laut sehingga terjadi proses perpindahan panas. Suhu refrigerant yang awalnya rendah naik menjadi kurang lebih $5^{\circ} \mathrm{C}$ sedangkan suhu air laut turun dari $28{ }^{\circ} \mathrm{C}$ menjadi $5{ }^{\circ} \mathrm{C}$. Refrigerant kemudian dialirkan kembali ke kompresor dalam bentuk uap yang bertekanan rendah.

Air laut yang telah didinginkan didalam palka oleh refrigerant kemudian siap untuk mendingin ikan. Suhu di dalam palka dapat terjaga sesuai suhu yang di inginkan karena proses pendinginan air laut menggunakan refrigerant berlangsung secara terus menerus.

\section{Pembahasan}

Kapal ikan pelat datar ini beroperasi di sekitar laut Sulawesi. Kapal bergerak dari pelabuhan Dede Kab. Toli-toli menuju ke arah laut Sulawesi sebagai fishing ground sejauh 50-60 mil. Dengan kecepatan 9 knot maka kapal akan sampai ke fishing ground dalam waktu 5-6 jam. Sedangkan waktu penangkapan di fishing ground diasumsikan 10-12 jam. Dengan demikian maka waktu operasi mencapai satu hari satu malam.

Sistem RSW pada kapal pelat datar akan memenuhi kebutuhan beban pendingin yang dibutuhkan agar suhu ikan di dalam palka terjaga. Jika beban pendingin harus sama dengan beban panas, dapat diketahui bahwa sistem RSW yang direncanakan ini membutuhkan waktu selama 2,5 jam untuk mendinginkan ruangan palka menjadi $5{ }^{\circ} \mathrm{C}$.

Kesebandingan antara beban pendingin dengan beban panas berada pada nilai $143,14: 107,353$. hal ini menunjukkan bahwa beban pendingin yang dihasilkan oleh refrigerant mampu mendinginkan air laut menjadi $5^{\circ} \mathrm{C}$.

Jika beban pendingin $Q_{\text {evaporator sebesar }}$ $107,353 \mathrm{~kW}$ sedangkan Qpalka sebesar 269,43 kW, maka dalam memenuhi kebutuhan pendingin palka dibutuhkan waktu kurang lebih 2,1 sampai dengan 2,5 jam.

Nilai-nilai yang diperoleh di atas menunjukkan bahwa sistem pendingin RSW yang di rencanakan pada kapal pelat datar dapat berfungsi dengan baik untuk mendinginkan muatan yang ditampung di dalam palka dan terjaga pada suhu $5^{\circ} \mathrm{C}$.

\section{Kesimpulan}

Pada penelitian, sebuah sistem Refrigated Sea Water dirancang. Dari desain sistem Refrigerated Sea Water (RSW) pada kapal ikan pelat datar 10 GT, dapat diketahui bahwa desain yang dibuat membutuhkan palka atau ruang muat ikan yang dapat menjaga suhu muatan ikan sampai dengan suhu $5{ }^{\circ} \mathrm{C}$.

\section{Referensi}

[1] Suganda. 2017. Desain Sistem Pendingin Slurry Ice Pada Kapal Perikanan 30 GT. Surabaya. Institut Teknologi Sepuluh Nopember.

[2] Riyadi, Mamat., Budiarto, Untung., dan Budi Santosa, Ari Wibawa. 2016. Analisa Teknis Dan Ekonomis Penggunaan Sistem Pendingin Refrigerated Sea Water (RSW) Pada Kapal Ikan Tradisional. Semarang: Universitas Diponegoro.

[3] Siagian, Saut. 2017. Perhitungan Beban Pendingin Pada Cold Storage Untuk Penyimpanan Ikan Tuna Pada PT.X. Jakarta Selatan: UPN Veteran Jakarta.

[4] Andhik Kurniawan, Mochammad., Baheramsyah, Alam., dan WA, Soemartojo. 2014. Desain Sistem Spray RSW 
(Refrigerated Sea Water) Untuk Ruang Palka Kapal Purse Seine 40 GT. Surabya: Institut Teknologi Sepuluh Nopember.
[5] Effendi, Rifki. Perancangan Refrigerated Sea Water (Rsw) Sistem Kering Pada Kapal Ikan Kayu Lapis Fiber 58 GT Dengan Kapasitas Palka 45 m3. Jakarta: Universitas Muhammadiyah. 